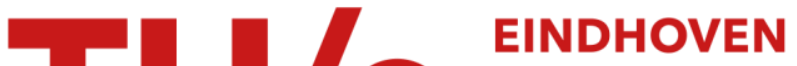 UNIVERSITY OF TECHNOLOGY
}

\section{Seeded emulsion polymerization of butadiene. 2. Effects of persulfate and tert-dodecyl mercaptan}

\section{Citation for published version (APA):}

Verdurmen, E. M. F. J., Geurts, J. M., Verstegen, J. M., Maxwell, I. A., \& German, A. L. (1993). Seeded emulsion polymerization of butadiene. 2. Effects of persulfate and tert-dodecyl mercaptan. Macromolecules, 26(23), 62896298. https://doi.org/10.1021/ma00075a026

DOI:

10.1021/ma00075a026

Document status and date:

Published: 01/01/1993

\section{Document Version:}

Publisher's PDF, also known as Version of Record (includes final page, issue and volume numbers)

\section{Please check the document version of this publication:}

- A submitted manuscript is the version of the article upon submission and before peer-review. There can be important differences between the submitted version and the official published version of record. People interested in the research are advised to contact the author for the final version of the publication, or visit the $\mathrm{DOI}$ to the publisher's website.

- The final author version and the galley proof are versions of the publication after peer review.

- The final published version features the final layout of the paper including the volume, issue and page numbers.

Link to publication

\section{General rights}

Copyright and moral rights for the publications made accessible in the public portal are retained by the authors and/or other copyright owners and it is a condition of accessing publications that users recognise and abide by the legal requirements associated with these rights.

- Users may download and print one copy of any publication from the public portal for the purpose of private study or research.

- You may not further distribute the material or use it for any profit-making activity or commercial gain

- You may freely distribute the URL identifying the publication in the public portal.

If the publication is distributed under the terms of Article 25fa of the Dutch Copyright Act, indicated by the "Taverne" license above, please follow below link for the End User Agreement:

www.tue.nl/taverne

Take down policy

If you believe that this document breaches copyright please contact us at:

openaccess@tue.nl

providing details and we will investigate your claim. 


\title{
Seeded Emulsion Polymerization of Butadiene. 2. Effects of Persulfate and tert-Dodecyl Mercaptan
}

\author{
Edwin M. Verdurmen, John M. Geurts, John M. Verstegen, \\ Ian A. Maxwell, ${ }^{\dagger}$ and Anton L. German \\ Laboratory of Polymer Chemistry, Eindhoven University of Technology, P.O. Box 513, \\ 5600 MB Eindhoven, The Netherlands \\ Received March 8, 1993; Revised Manuscript Received July 9, $1993^{\circ}$
}

\begin{abstract}
The kinetics of the emulsion polymerization of butadiene at $60^{\circ} \mathrm{C}$ in Smith-Ewart interval III were investigated using sodium peroxodisulfate (persulfate) as initiator. The aim of this work was to elucidate and model the persulfate initiator efficiency. Monomer conversion was based on gravimetrically calibrated on-line densitometry. Plots of the product of the propagation rate coefficient, $k_{\mathrm{p}}$, and the average number of radicals per particle, $n$, versus initiator concentration showed minimal dependence on the initiator concentration if tert-dodecyl mercaptan (TDM) was present during polymerization. These results could not be modeled using normal emulsion polymerization theory. The model used in the absence of TDM fits two separate sets of data, $n$ versus particle diameter and $n$ versus initiator concentration. In the absence of TDM, $n$ depends strongly on the initiator concentration. The significant effect of TDM is ascribed to a decrease in the radical desorption. A possible effect on the radical absorption is refuted on the basis of theory and experiment.
\end{abstract}

\section{Introduction}

Important papers on the butadiene emulsion polymerization have been published as a result of the synthetic rubber program ${ }^{1}$ by Kolthoff $e t a l .^{2}$ and by Morton et al. $^{3-6}$ Important for this paper are the observations by Bovey et al. ${ }^{1}$ and Blackley, ${ }^{7}$ who reported a weak dependence of the rate of polymerization on the initiator concentration. This puzzling behavior is confirmed by exhaustive experimental evidence reported by Weerts et $a l .^{8-14}$ In the latter work extremely low values of the initiator exponent with regard to polymerization rate per particle have been found. Because this work dealt with $a b$ initio experiments, the rate of polymerization per particle was used to compare separate experiments. Weerts et al. ${ }^{14}$ explain the weak dependence of the rate of polymerization on the initiator concentration by an extremely low initiator efficiency, rendering this rate independent of the initiator concentration and particle number. However, this explanation would imply a change of initiator efficiency as a function of the initiator concentration exactly compensating for the effect of the initiator concentration: there is no experimental evidence for such a mechanism. Moreover, in light of recent advances in the theoretical description of radical absorption (entry) ${ }^{16}$ this seems unlikely. The new entry model, along with uncertainties in the particle number invoked by the $a b$ initio experiments reported in the literature, and also the recently available value of the rate coefficient of propagation for butadiene have inspired the present efforts in obtaining new data from well-defined seeded emulsion polymerization experiments in which the persulfate concentration is varied systematically.

Until now no explanation has been given at present for the relatively low rate of polymerization generally observed in the butadiene emulsion polymerization, since these low rates cannot be explained by a low propagation rate constant since the experimentally measured propagation

* Author to whom correspondence should be addressed.

† Current address: Sydney University Polymer Centre, School of Chemistry F11, University of Sydney, Sydney, NSW 2006, Australia.

- Abstract published in Advance ACS Abstracts, October 1, 1993. rate coefficient is not exceptionally small. ${ }^{16,17}$ At present there are two remaining observations on the rate of emulsion polymerization of butadiene that are not adequately explained in the open literature: (1) the "observed" near independence of the rate of polymerization on the initiator concentration and (2) the promoting effect of dodecyl mercaptans on the rate of polymerization. ${ }^{2}$

The present paper primarily focuses on the first problem. However, it will become evident from this paper that both problems, the independence of the rate on the initiator concentration and the effect of mercaptans, are interlinked by a complex mechanism. Seeded emulsion polymerizations were conducted in order to clarify the effect of the persulfate concentration on the entry of free radical into particles and also to measure the average number of radicals per particle.

\section{Experimental Section}

Butadiene (DSM Chemicals, Geleen, The Netherlands) was distilled directly from a $27 \cdot \mathrm{L}$ storage vessel into a cooled steel recipient. A two-isomer mixture of tert-dodecyl mercaptan (TDM) was used (Fluka AG, Buchs, Switzerland); sodium peroxodisulfate (Fluka AG, Buchs, Switzerland), sodium dodecyl sulfate (p.a. Merck, Darmstadt, Germany), and sodium carbonate (p.a. Merck, Darmstadt, Germany) were all used without further purification. Water was doubly distilled and purged with nitrogen to remove oxygen.

\section{Emulsion Polymerizations}

Experimental details are elaborately explained elsewhere. ${ }^{16}$ A summary of features important for this paper is presented below. The seeded emulsion polymerizations were carried out in a cylindrical stainless steel reactor. The reactor was connected with a remote density meter (Anton Paar DMA 401, Graz, Austria) linked to a registration unit (Anton Paar DMA 60, Graz, Austria) and a computer. The reaction mixture was pumped with a piston-membrane pump (Orlita KG, MK 10, Giessen/ Lahn, Germany) from the reactor through the density cell and back into the reactor. Gravimetrical conversion data are used to calibrate on-line density data. Gravimetric samples were collected using a high-pressure proof syringe. 
Table 1. Recipe 1 and a Description of the Seeded Interval III Emulsion Polymerization Beginning at $w_{\mathrm{p}}=0.6$

\begin{tabular}{|c|c|c|}
\hline component & recipe description & recipe/(g) \\
\hline polybutac & $w_{p}=0.6$ & 97.5 \\
\hline buta & $\begin{array}{l}40 \% \text { of max solid content } \\
\text { at } 100 \% \text { convn }\end{array}$ & 65 \\
\hline water & $\begin{array}{l}90 \% \text { of reaction mixture } \\
\text { variable }^{a}\end{array}$ & 877.5 \\
\hline $\begin{array}{l}\text { sodium peroxodisulfate } \\
\text { tert-dodecyl mercaptan }\end{array}$ & $1 \%$ on monomer & 0.65 \\
\hline
\end{tabular}

${ }^{a}$ Initiator and buffer are used in equivalent concentrations. However the buffer concentration is never reduced below $10^{-3}$ $\mathrm{mol} \cdot \mathrm{dm}^{-3}$.

Table II. Recipe $2^{b}$ and a Description of the Seeded Interval III Emulsion Polymerization Beginning at $w_{p}=0.72$

\begin{tabular}{llc}
\hline \multicolumn{1}{c}{ component } & \multicolumn{1}{c}{ recipe description } & recipe/(g) \\
\hline polybutadiene & $w_{\mathrm{p}}=0.72$ & 102 \\
butadiene & $\mathbf{2 8 \%}$ of max solid content & 39.7 \\
& $\quad$ at $100 \%$ convn & \\
water & $90 \%$ of reaction mixture & 918.4 \\
sodium carbonate & $\begin{array}{l}\text { variable } \\
\text { sodium persulfate }\end{array}$ & \\
variable & \\
tert-dodecyl mercaptan & $1 \%$ on monomer (variable) & 0.4
\end{tabular}

a Initiator and buffer are used in equivalent concentrations. However, the buffer concentration is never reduced below $10^{-3}$ $\mathrm{mol} \cdot \mathrm{dm}^{-3}, b$ See Table I for recipe 1.

From these samples the conversion was calculated. Conversions assessed in this way were accurate to within $0.5 \%$. The density data converted into conversion data are transformed into plots of $-\ln (1-x)$ versus time. The slope of the linear part of these plots is determined by linear regression. The average particle diameter and particle size distribution were measured by transmission electron microscopy (TEM; Jeol 2000 FX) in combination with $\mathrm{OsO}_{4}$ staining techniques. The particle diameters mentioned in this paper are weight-average diameters. Particle size distributions of the seed latexes used are extremely narrow, typical polydispersity $d_{\mathrm{w}} / d_{\mathrm{n}}=1.01$. The particle size distributions of the particles with diameters below $100 \mathrm{~nm}$ are more broad but never surpass $d_{\mathrm{w}} / d_{\mathrm{n}}=1.1$.

Recipe 1, listed in Table I, is used for all polymerizations unless stated otherwise and is developed to minimalize the head space in the reactor. Recipe 1 is also designed to start the polymerizations at the beginning of interval III at weight fractions of polymer in the particle, $w_{\mathrm{p}}=$ 0.6. ${ }^{14}$ In Table II a second recipe is listed. This recipe 2 is developed to start a seeded polymerization later in interval III at $w_{\mathrm{p}}=0.72$.

Recipe 2 was formulated as a result of the observation of two long linear regions in plots of $-\ln (1-x)$ versus time in interval III of a butadiene emulsion polymerization. ${ }^{16}$ It was observed that the shift from the first to the second linear region was determined by the conversion or weight fractions of polymer. In Figures 1 and 2 the weight fractions of polymer at which the polymerizations shift from the first to the second linear region are shown for experiments performed at a wide range of particle sizes and initiator concentrations.

Recipe 2 is developed to start a seeded polymerization further into interval III at $w_{\mathrm{p}}=0.72$. In Table III values of $k_{\mathrm{p}} \bar{n}$ versus particle diameter and initiator concentration obtained by using recipes 1 and 2 are compared. The values compare quite acceptably and well within experimental error. In Figure 3 a $-\ln (1-x)$ versus time curve obtained from an experiment utilizing recipe 2 is shown.

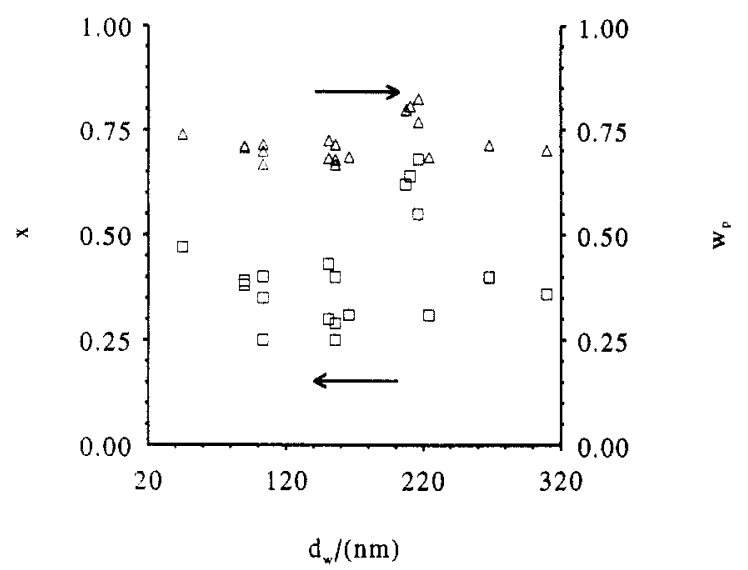

Figure 1. $w_{\mathrm{p}}(\Delta)$ and $x(\square)$ at which polymerizations shift from the first to the second linear region versus seed latex particle diameter, $d_{w}$, using recipe 1 .

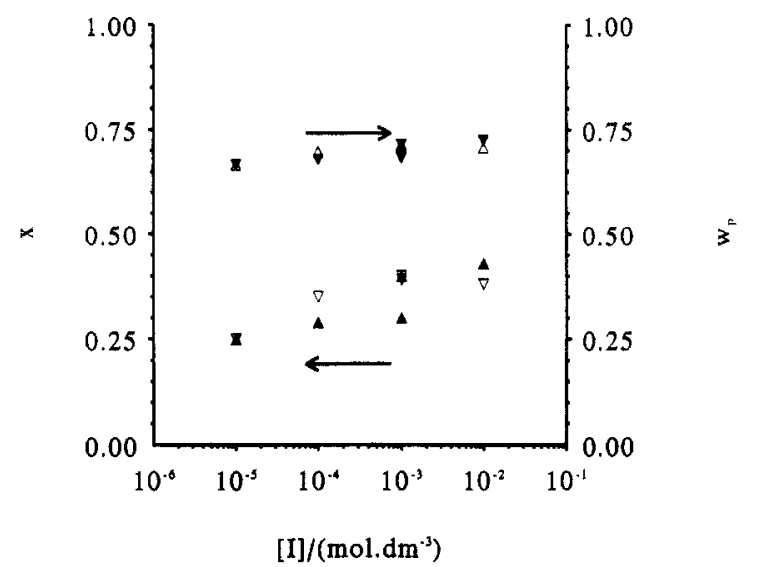

Figure 2. $w_{\mathrm{p}}$ and $x$ (closed symbols, $d_{\mathrm{w}}=150 \mathrm{~nm}$; open symbols, $d_{w}=90 \mathrm{~nm}$ ) at which polymerizations shift from the first to the second linear region versus initiator concentration, [I], using recipe 1 .

Table III. Comparison of $k_{p} n$ Values from Experiments Utilizing Recipes 1 and 2 at Various Particle Diameters, $d_{w}$, and Initiator Concentrations, [I]

\begin{tabular}{cccc}
\hline & & \multicolumn{2}{c}{$k_{\mathrm{pa}} /\left(\mathrm{dm}^{3} \cdot \mathrm{mol}^{-1} \cdot \mathrm{s}^{-1}\right)$} \\
\cline { 3 - 4 }$d_{\mathrm{w}}{ }^{2} /(\mathrm{nm})$ & {$[\mathrm{I}] \times 10^{3} /\left(\mathrm{mol} \cdot \mathrm{dm}^{-3}\right)$} & recipe $1^{b}$ & recipe 2 \\
\hline 100 & 10 & 41 & 42 \\
100 & 1 & 44 & 46 \\
100 & 1 & 64 & \\
100 & 0.1 & 41 & 36 \\
100 & 0.01 & 14 & 13 \\
45 & 10 & 6 & 6 \\
225 & 10 & 122 & 102
\end{tabular}

a Experiments in recipes 1 and 2 are performed on different seed latexes. The particle diameters of these experiments are within 10 $n m$ (i.e., well within experimental error). ${ }^{b}$ Determined from the second linear region.

Note that the plot shows only one linear region starting close to zero time.

From Table III and Figures 1-3 the following can now be concluded:

1. The two linear regions observed when using recipe 1 are not an effect of retardation nor a kinetically determined approach to steady state since a number of polymerizations show the same behavior irrespective of particle size and initiator concentration which are both varied over a wide range.

2. Seeded emulsion polymerizations of butadiene started in interval III at $w_{\mathrm{p}}=0.72$ show only one linear region. This steepest linear region is kinetically determined and not influenced by the $w_{\mathrm{p}}$ at which the seeded 


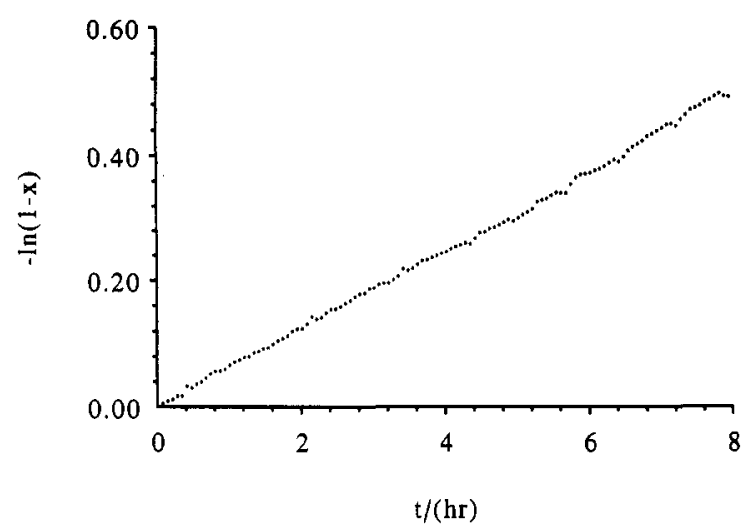

Figure 3. $-\ln (1-x)$ versus time from an experiment using recipe 2. The plot shows only one constant slope from which the maximum product of $k_{\mathrm{p}} \bar{n}$ can be determined.

polymerization is started. The $k_{\mathrm{p}} \tilde{n}$ values are determined from the slope of this second linear region and are the maximum values of $k_{\mathrm{p}} \bar{n}$.

An explanation as to why the seeded emulsion polymerization of butadiene shows this unusual behavior is unclear as yet. The use of recipe 2 is more convenient since now the slope of the curves of $-\ln (1-x)$ versus time used to calculate $\bar{n}$ can be determined from the beginning of the reaction. This is useful when reaction conditions leading to extremely low values of $\bar{n}$ are observed.

The polybutadiene in the recipes is added in the form of a seed latex made by emulsifier free emulsion polymerization. The preparation of this seed latex is discussed in detail elsewhere. ${ }^{18,19}$ All the seed latexes are prepared under comparable process conditions. The seed latexes used were dialyzed until constant low serum conductivity $\left(<20 \mu \mathrm{S} \cdot \mathrm{cm}^{-1}\right)$ to remove traces of initiator. Special care is taken to dialyze the seed latexes to ensure that even when using low initiator concentrations in the recipes the effect of the residual initiator from seed latex preparation was negligible. The monomer was allowed to swell the seed latex at $25^{\circ} \mathrm{C}$ for $24 \mathrm{~h}$. After swelling the initiator was added as a $50-\mathrm{mL}$ aqueous solution via a gas-tight syringe through a valve. For recipe 1 the beginning of polymerization was taken as the time when the temperature began rising from room temperature to $60^{\circ} \mathrm{C}$. When utilizing recipe 2 the initiator was injected into the reactor when the reaction mixture was at reaction temperature. Hence, the injection time of the initiator was taken as the start of the polymerization. No retardation was noticed in any of the polymerizations.

The average particle diameter and the particle size distribution were measured using calibrated transmission electron microscopy (TEM; Jeol 2000 FX) in combination with $\mathrm{OsO}_{4}$ staining techniques. Typically some 1000 particles were counted (TGA-10 particle analyzer, Zeiss, Oberkochen, Germany) on a micrograph taken from various parts of the TEM sample grid. Calibration of the measured particle diameters was performed with a specimen of known diameter. The particle diameters mentioned in this paper are weight-average diameters $d_{w}$.

\section{Theory}

Seeded emulsion polymerizations were performed in the Smith-Ewart interval III regime. An interval III analysis is relatively straightforward and derived from general kinetics: ${ }^{20}$

$$
-\frac{\mathrm{d} X}{\mathrm{~d} t}=\frac{k_{\mathrm{p}} \bar{n} C_{\mathrm{m}} N}{n_{\mathrm{m} 0} N_{\mathrm{av}}}
$$

where $\mathrm{X}$ is the fractional monomer conversion, $k_{\mathrm{p}}$ is the propagation rate coefficient $\left(\mathrm{dm}^{3} \cdot \mathrm{mol}^{-1} \cdot \mathrm{s}^{-1}\right), \bar{n}$ is the average number of radicals per particle, $C_{\mathrm{m}}$ is the monomer concentration in the particles $\left(\mathrm{mol} \cdot \mathrm{dm}^{-3}\right), N$ is the number of particles per volume of the water phase $\left(\mathrm{dm}^{-3}\right), N_{\mathrm{av}}$ is Avogadro's constant $\left(\mathrm{mol}^{-1}\right)$, and $n_{\mathrm{m} 0}$ is the initial number of moles of monomer present per unit volume of the water phase $\left(\mathrm{mol} \cdot \mathrm{dm}^{-3}\right)$ and therefore a constant. In interval III the monomer concentration in the particles is not constant and the relationship between the conversion and monomer concentration is described by:

$$
x=1-C_{m} / C_{m 0}
$$

where $x$ is the monomer conversion in interval III defined according to $x=0$ at weight fraction of polymer $w_{\mathrm{p}}=0.6$ and $x=1$ at $w_{\mathrm{p}}=1 . C_{\mathrm{m} 0}$ is the monomer concentration in the particles at the beginning of interval III. Introducing the result of eq 2 into eq 1 yields

$$
\frac{-\mathrm{d} \ln (1-x)}{\mathrm{d} t}=\frac{k_{\mathrm{p}} \bar{n} C_{\mathrm{m} 0} N}{N_{\mathrm{av}} n_{\mathrm{m} 0}}
$$

From the steady-state regime of a plot of $-\ln (1-x)$ versus time the product of $k_{\mathrm{p}} \bar{n}$ can be calculated since all other variables on the right-hand side of eq 3 are known and constant. Note that a value for $\bar{n}$ can be calculated from such a plot given the value of $k_{\mathrm{p}}$ reported by the present authors elsewhere. ${ }^{16}$ As is evident from eq 3 a value of $C_{\mathrm{m} 0}$ is needed to calculate $\tilde{n}$. Using recipe 1 the value of $C_{m 0}$ is taken as the value at the beginning of interval III $\left(w_{\mathrm{p}}=0.60^{14}\right)$. This value, however, is linked to the definition of the monomer conversion in interval III, $x$, as can be deduced from eq 2 . Using recipe $2, C_{\mathrm{m} 0}$ is taken as the value at $w_{\mathrm{p}}=0.72$; consequently $x$ is now defined according to $x=0$ at $w_{\mathrm{p}}=0.72$ and $x=1$ at $w_{\mathrm{p}}=1$. The value of $C_{m 0}$ then is simply calculated from the added quantities of monomer and polymer according to:

$$
C_{\mathrm{m} 0}=\frac{M^{\text {but }} / \mathrm{MW}^{\text {but }}}{M^{\text {but }} / \rho_{\text {but }}+M^{\mathrm{PB}} / \rho_{\mathrm{PB}}}
$$

where $M^{\text {but }}$ is the initial mass of butadiene utilized (see Tables I and II), MWbut is the molecular weight of butadiene, $\rho_{\text {but }}$ is the density of butadiene at $60^{\circ} \mathrm{C}$, and $M^{\mathrm{PB}}$ is the initial mass of polybutadiene utilized (see Tables I and II). The slight volume contraction that occurs when mixing polybutadiene and butadiene is not compensated for, causing a small systematic error in $C_{\mathrm{m} 0}$. The monomer dissolved in the water phase is not taken into account in

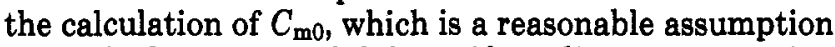
given the low water solubility of butadiene at saturation pressure, $M_{\text {aq }}$.

The monomer concentration in the aqueous phase, $M_{\mathrm{aq}}$, is an important parameter in the model calculations described later on and is assumed to be in thermodynamic equilibrium with the monomer concentration in the particles. Although $C_{\mathrm{m} 0}$ can be calculated in a simple manner by neglecting the amount of monomer in the aqueous phase, this evidently cannot be the case when $M_{\mathrm{aq}}$ has to be calculated as well. Recently Maxwell et al..$^{21}$ reported a semiempirical approach in calculating the equilibrium monomer concentration in the particles and in the aqueous phase of swollen latexes. Assuming monomer partitioning is fast as compared with polymerization, the $C_{\mathrm{m}}$ and $M_{\mathrm{aq}}$ during polymerization can be calculated according to: $:^{21}$

$$
\ln \left(1-v_{\mathrm{p}}\right)+v_{\mathrm{p}}\left(1-1 / M_{\mathrm{n}}\right)+\text { corr. }=\ln \left[M_{\mathrm{aq}} / M_{\mathrm{aq}, \mathrm{sat}}\right]
$$

where $v_{\mathrm{p}}$ is the volume fraction of polymer in the particle phase, $M_{n}$ is the number-average degree of polymerization 


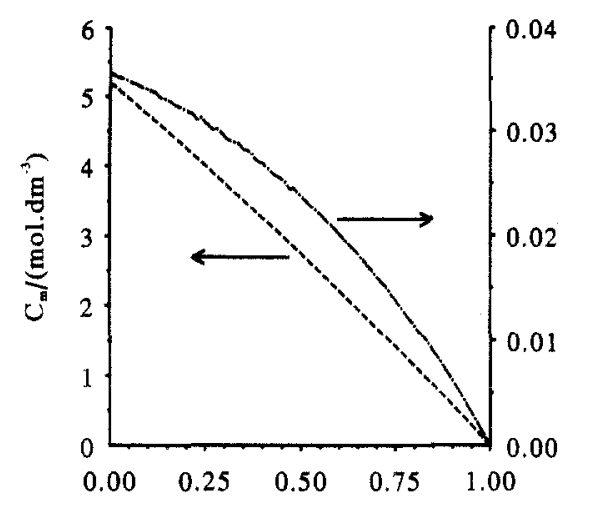

$\mathrm{x}$

Figure 4. Monomer concentration in the particles, $C_{\mathrm{m}}(--)$, and monomer concentration in the aqueous phase, $M_{\mathrm{sq}}(-\cdot-)$ versus fractional monomer conversion in interval III, $x$.

of the swollen polymer, and $M_{\mathrm{Bq}, \mathrm{sat}}$ is the saturation concentration of monomer in the aqueous phase. The term "corr." is a correction factor adequately explained elsewhere ${ }^{21}$ and calculated according to:

$$
\text { corr. }=-\left[\ln \left(1-v_{\mathrm{p}, \mathrm{sat}}\right)+v_{\mathrm{p}, \mathrm{sat}}\left(1-1 / M_{\mathrm{n}}\right)\right]
$$

The term $M_{\mathrm{n}}$ is usually large enough to allow $1 / M_{\mathrm{n}} \approx 0$. The quantities $C_{\mathrm{m}}$ and $M_{\mathrm{aq}}$ can be found by solving eqs 5 and 6 and mass balance considerations. A numerical solution of these equations is needed since the equations are nonlinear. $C_{\mathrm{m}}$ and $M_{\mathrm{aq}}$ versus $w_{\mathrm{p}}$ for butadiene-swollen polybutadiene latexes are shown in Figure 4.

Calculating $M_{\mathrm{aq}}$ in this fashion may introduce a small systematic error in later model calculations. However, this is unavoidable since no experimental $M_{\mathrm{aq}}$ data are available for the butadiene system and experimental data are difficult to obtain due to the gaseous nature of butadiene. The model calculations are not strongly affected by small deviations in $M_{\mathrm{aq}}$.

\section{Background Section}

Some important earlier results deduced from $a b$ initio interval II and III analysis of the emulsion polymerization of butadiene ${ }^{14}$ need to be evaluated. From $a b$ initio interval II analysis it was shown that the effects of process and recipe parameters (except temperature) on the polymerization kinetics all depend on their effect on particle size: there is a decrease in the rate per particle with decreasing particle size. In interval III the bimolecular termination rate coefficients would be expected to vary significantly with the weight fraction of polymer $\left(w_{\mathrm{p}}\right)^{22,23}$ Hence, the linearity of the plots $-\ln (1-x)$ versus time over a wide range of initiator and electrolyte concentrations and particle sizes indicates the following:

1. Termination is not rate determining and thus instantaneous upon entry of free radicals into particles. Plotting $\bar{n}$ versus particle diameter showed that $\bar{n}$ rises with increasing particle diameter. This leads to the conclusion that butadiene obeys Smith-Ewart case I kinetics at $62^{\circ} \mathrm{C}$ and at particle diameters below $200 \mathrm{~nm}$. This is an important consideration since in the SmithEwart case II regime the rate of polymerization, $R_{\text {pol }}$, is independent of initiator concentration. Thus the reported near independence of the $R_{\mathrm{pol}}$ on initiator concentration cannot be explained by assuming ideal case II behavior. On the other hand, experiments conducted to clarify the effect of initiator efficiency should not be performed in the case II regime (i.e., not at particle diameter $>200 \mathrm{~nm}$ ).

2. Both $\bar{n}$ and $k_{\mathrm{p}}$ are constant during a particular polymerization up to $w_{\mathrm{p}}=0.85$, since it is highly unlikely that $\bar{n}$ and $k_{\mathrm{p}}$ would counterbalance over such a wide range of experimental conditions. This is because the righthand side of eq 1 consists of only constants within a particular polymerization. Thus for every separate seeded polymerization a unique value of $\bar{n}$ can be determined given a value for the propagation rate coefficient, $k_{\mathrm{p}}$. The value used in this paper will be $k_{\mathrm{p}}=320 \mathrm{dm}^{3} \cdot \mathrm{mol}^{-1} \cdot \mathrm{s}^{-1} \cdot 16$

Several important results from seeded emulsion polymerizations of butadiene in interval III, reported elsewhere, ${ }^{16}$ need to be evaluated.

1. Data of $k_{\mathrm{p}} \bar{n}$ versus particle diameter show a plateau in $\bar{n}$ for particle sizes above $200 \mathrm{~nm}$ from which a value of the propagation rate coefficient was determined, ${ }^{16} k_{\mathrm{p}}$ $=320 \pm 50 \mathrm{dm}^{3} \cdot \mathrm{mol}^{-1} \cdot \mathrm{g}^{-1}$. This value agrees well with a value measured by laser flash photolysis reported by Deibert et al. ${ }^{17}$ It must be noted that these authors did not mention how problems like branching and possible cross-linking of the polybutadiene could interfere with obtaining the necessary molecular weight data from sizeexclusion chromatography.

2. Data of $k_{\mathrm{p}} \bar{n}$ versus particle diameter show a nonplateau region as a consequence of the shift from case II to case I kinetics and therefore a strong indication of the existence of case I and case II regions.

3. Data of $k_{\mathrm{p}} \bar{n}$ versus particle diameter are fitted well with a relatively simple model utilizing, among other things, the following kinetic parameters: the rate coefficient for radical termination in the water phase, $k_{t}$, and the rate coefficient for radical transfer to monomer, $k_{t r}$; the latter has been determined ${ }^{16}$ to lie within the limits $0.01-0.1 \mathrm{dm}^{3} \cdot \mathrm{mol}^{-1} \cdot \mathrm{s}^{-1}$.

The evaluation of earlier work on the butadiene system makes clear the following:

1. An experiment designed to monitor the effect of the initiator concentration should be performed using seed latexes with a particle diameter well below $200 \mathrm{~nm}$ to avoid case II kinetics and the consequent insensitivity of the rate of polymerization to initiator concentration as explained by the Smith-Ewart theory.

2. When using particle sizes below $200 \mathrm{~nm}$, an effect of the initiator concentration must be found if butadiene is to follow the Smith-Ewart theory. If not, the use of the previously mentioned model calculations partially using the Smith-Ewart model is not a priori valid.

Model Evaluation of the Entry of Radicals in Particles. The entry model for absorption of radicals into latex particles for persulfate-initiated emulsion polymerization, as reported by Maxwell et al., ${ }^{15}$ describes the mechanism of entry as follows. A sulfate radical dissolved in the water phase will react with monomer also dissolved in the water phase and form oligomeric radicals. This oligomeric radical will grow to become surface active after addition of $z$ monomer units. After this growth, entry is supposed to be instantaneous. Thus the rate-determining step for entry is the growth of a sulfate radical to become a surface-active oligomer. The degree of polymerization of a surface-active radical, $z$, is an important factor in determining the initiator efficiency. This is intuitively clear when considering the possibility of termination in the water phase during the growth of the oligomer. The entry rate coefficient for radicals into particles $(\rho)$ as reported by Maxwell et al. ${ }^{15}$ is given by:

$$
\rho=\left[\frac{2 k_{\mathrm{d}}[I] N_{\mathrm{av}}}{N}\right]\left[\frac{k_{\mathrm{t}}\left[T^{*}\right]}{k_{\mathrm{p}} M_{\mathrm{aq}}}+1\right]^{1-z}
$$

where $\rho$ is the entry rate coefficient, $k_{\mathrm{d}}$ is the dissociation rate coefficient of persulfate, [I] is the initiator concentration, $k_{\mathrm{t}}$ is the bimolecular termination rate coefficient 
Table IV. Numeric Values of the Parameters and Recipe Information Used in the Model Calculations

\begin{tabular}{|c|c|c|c|}
\hline param & valued & param & value \\
\hline $\begin{array}{l}k_{\mathrm{d}} \\
k_{\mathrm{t}}\end{array}$ & $\begin{array}{l}6.3 \times 10^{-6} / \mathrm{s}^{-1} \\
7 \times 10^{9} /\left(\mathrm{dm}^{3} \cdot \mathrm{mol}^{-1} \mathrm{~s}^{-1}\right)\end{array}$ & $\begin{array}{l}k_{\mathrm{po}} \\
\text { [I] (variable) }\end{array}$ & $\begin{array}{l}\approx k_{\mathrm{p}} /\left(\mathrm{dm}^{3} \cdot \mathrm{mol}^{-1} \cdot \mathrm{s}^{-1}\right) \\
10^{-5}-10^{-2} /\left(\mathrm{mol}^{-1} \cdot \mathrm{dm}^{-3}\right)\end{array}$ \\
\hline$z$ & & $M^{\text {but }}$ & $65^{a} / 39.7^{b} / g$ \\
\hline$k_{\mathrm{p}}$ & $320 / /$ & $M^{\mathrm{PB}}$ & $2^{b} / g$ \\
\hline$\stackrel{M_{\mathrm{eq}}}{D^{\prime \prime}}$ & $37 \times 10^{-3} /\left(\mathrm{mol}^{-\mathrm{dm}^{-3}}\right)$ & $M_{\mathrm{w}}$ & $877.5^{a} / 918.4^{b} / \mathrm{g}$ \\
\hline & 15 & $\rho_{\mathrm{PB}^{c}}{ }^{\rho_{\mathrm{put}^{c}}}$ & $\begin{array}{l}0.86 /\left(\mathrm{g}^{\circ} \mathrm{cm}^{-3}\right) \\
0.57 /\left(\mathrm{g} \cdot \mathrm{cm}^{-3}\right)\end{array}$ \\
\hline$k$ & $0.1-0.01 /\left(\mathrm{dm}^{3} \cdot \mathrm{mol}^{-1} \cdot \mathrm{g}^{-1}\right)$ & $\begin{array}{l}\rho_{\text {but }} \\
\rho_{\mathbb{w}^{c}}\end{array}$ & $\begin{array}{l}0.57 /\left(\mathrm{g}^{\circ} \cdot \mathrm{cm}^{-3}\right) \\
0.988\left(\mathrm{~g}^{-3} \mathrm{~cm}^{-3}\right)\end{array}$ \\
\hline
\end{tabular}

a The amounts added in recipe 1 as listed in Table $I .{ }^{b}$ The amounts added in recipe 2 as listed in Table II. ' The density values at $60^{\circ} \mathrm{C}$ are used.

of two radicals in the water phase, and $z$ is the degree of polymerization that causes an oligomeric radical with a sulfate end group to become surface active. The factors within the left-hand-side brackets represent $100 \%$ efficiency. The right-hand-side brackets enclose an efficiency factor strongly influenced by the factor $z$. Maxwell et $a l .{ }^{15}$ report theoretically derived values of $z=2$ for styrene and values of $z=2-4$ for butadiene. Intuitively the value of $z=3$ for butadiene is acceptable considering the similarity between a butadiene oligomer of degree of polymerization $z=3$ with a sulfate end group and wellknown surfactants like sodium dodecyl sulfate. In this paper a new limit in the entry rate coefficient equation is proposed which is of particular importance to the butadiene system. Introducing the result ${ }^{15,24}\left[\mathrm{~T}^{\bullet}\right]=\left(2 k_{\mathrm{d}}[\mathrm{I}] /\right.$ $\left.k_{t}\right)^{0.5}$ (Maxwell et al. claim that using this result will lead to inaccuracy by at worst $10 \%$ ) into eq 7 yields

$$
\rho=\left[\frac{2 k_{\mathrm{d}}[I] N_{\mathrm{a}}}{N}\right]\left[\frac{2 k_{\mathrm{t}}{ }^{1 / 2} k_{\mathrm{d}}{ }^{1 / 2}[I]^{1 / 2}}{k_{\mathrm{p}} M_{\mathrm{aq}}}+1\right]^{1-z}
$$

Consider the low-efficiency limiting case in which:

$$
\frac{2 k_{\mathrm{t}}{ }^{1 / 2} k_{\mathrm{d}}{ }^{1 / 2}[I]^{1 / 2}}{k_{\mathrm{p}} M_{\mathrm{aq}}} \gg 1
$$

Incorporating this limit into eq 7 offers the possibility of determining how $\rho$ depends on the exponent of [I]:

$$
\rho=\left[\frac{2 k_{\mathrm{d}} N_{\mathrm{av}}}{N}\right]\left[\frac{2 k_{\mathrm{d}}{ }^{1 / 2} k_{\mathrm{t}}{ }^{1 / 2}}{k_{\mathrm{p}} M_{\mathrm{aq}}}\right]^{1-z}[I]^{3-z / 2}
$$

If this new limit holds, the result is particularly interesting in the case of butadiene since the reported value ${ }^{25}$ for $z$ $=3$ would reduce the dependence of the rate of radical entry on [I] to zero and explain the insensitivity of the rate of polymerization to the initiator concentration as reported in the literature. The validity of this new limit is examined in this paper by introducing values for important parameters used, such as the water solubility of butadiene and the aqueous bimolecular termination rate coefficient, $k_{\mathrm{t}}$.

The following brief discussion and Table IV present some information about the parameters used. The value for $k_{\mathrm{d}}$ used is reported in the literature and measured in the presence of butadiene in an emulsion system at $60^{\circ} \mathrm{C}$ : $6.3 \times 10^{-6} \mathrm{~s}^{-1} .^{8,26}$ From the literature it is known that bimolecular termination rate coefficients $\left(k_{t}\right)$ in aqueous media are on the order of magnitude of $10^{9}-10^{10}$ $\mathrm{dm}^{3} \cdot \mathrm{mol}^{-1} \cdot \mathrm{s}^{-1} \cdot{ }^{25,27-30}$ The $k_{\mathrm{p}}$ used in the entry theory is in fact the rate coefficient of propagation of a sulfate oligomer with degree of polymerization $i\left(\mathrm{SO}_{4}{ }^{-} \mathrm{M}_{\mathrm{i}}{ }^{*}\right)$ with monomer. This value is not necessarily the same as the long-chain limit of the propagation rate coefficient. The value of the long-chain limit of $k_{\mathrm{p}}$ is usually taken as the best approximation for the value of this short-chain $k_{\mathrm{p}}$ : whether

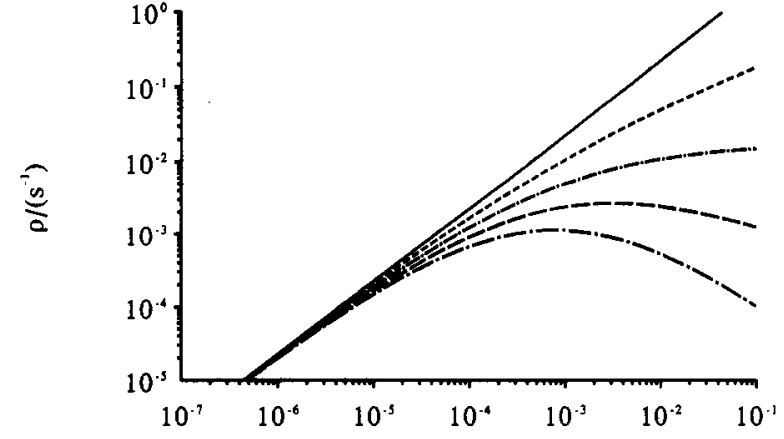

$[\mathrm{I}] /\left(\mathrm{mol} . \mathrm{dm}^{\cdot 3}\right)$

Figure 5. Model calculations for the radical entry rate coefficient, $\rho$, versus initiator concentration, [I], using the full eq 8 .

this is justified is unclear as yet. For $M_{\mathrm{aq}}$ the value of 37 $\times 10^{-3} \mathrm{~mol} \cdot \mathrm{dm}^{-3} 31$ is taken, since this value is measured at a saturation pressure of butadiene or a value belonging to the polymerization conditions via eqs 5 and 6 . The value for $z$ used is 3 monomer units, calculated from a method described by Maxwell et al. ${ }^{15}$

In Figure 5 model calculations of the entry rate coefficient using the full eq 8 (the new limit is not incorporated) are shown for the widest range in initiator concentration which is still physically feasible.

The new limit presented in this paper is valid as can be deduced from the asymptotic behavior of $\bar{n}$ at higher initiator concentration. Obviously the limit only describes an insensitivity of $\rho$ to the initiator concentration at high values of the latter above $10^{-2} \mathrm{~mol} \cdot \mathrm{dm}^{-3}$. At initiator concentrations, $[\mathrm{I}] \ll 10^{-2} \mathrm{~mol} \cdot \mathrm{dm}^{-3}$, $\rho$ rapidly decreases. Hence, this limit cannot be used to explain the independence of the rate on [I] at lower [I].

Model Evaluation of the Exit of Radicals from Particles. The first-order exit rate coefficient is given by: ${ }^{32}$

$$
k=k_{\mathrm{tr}} C_{\mathrm{m}} P
$$

where $k_{\text {tr }}$ is the rate coefficient for transfer to monomer and $P$ the probability of escape of a free monomeric radical given by competing rates of escape and propagation:

$$
k=k_{\mathrm{tr}} C_{\mathrm{m}}\left[\frac{k_{\mathrm{es}}}{k_{\mathrm{es}}+k_{\mathrm{p} 0} C_{\mathrm{m}}}\right]
$$

where $k_{\mathrm{p} 0}$ is the propagation rate coefficient of a single monomeric radical with a monomer unit and $k_{e s}$ is the escape rate coefficient of monomer from the particle given by:

$$
k_{\mathrm{eg}}=3 D^{\|} / R_{\mathrm{s}}{ }^{2} q
$$

where $R_{\mathrm{s}}$ is the swollen radius of the latex particles, $q$ is the partition coefficient of the monomeric radicals between the particle and water phases $\left(q=C_{\mathrm{m}} / M_{\mathrm{aq}}\right)$, and $D^{\prime \prime}$ is the diffusion coefficient of the monomeric radical in water. Introducing the expression for the first-order rate coefficient for escape in the final equation for the exit rate coefficient as proposed by Ugelstad and Hansen ${ }^{32}$ renders

$$
k=k_{\mathrm{tr}} C_{\mathrm{m}}\left[\frac{\frac{3 D^{\|}}{\left({ }^{1} /{ }_{2} d_{\mathrm{wg}}\right)^{2} q}}{k_{\mathrm{p} 0} C_{\mathrm{m}}+\frac{3 D^{\|}}{\left({ }^{1} / 2 d_{\mathrm{wg}}\right)^{2} q}}\right]
$$

where $d_{\text {wg }}$ is the swollen weight-average particle diameter. 
Table V. $k_{p} h$ Values from Experiments Utilizing Various Particle Diameters, $d_{\boldsymbol{m}}$, Particle Numbers, $N$, and Initiator Concentrations, [I]

\begin{tabular}{cccccc}
\hline $\begin{array}{c}{[\mathrm{I}] \times 10^{3} /} \\
\left(\mathbf{m o l}^{3} \cdot \mathbf{d m}^{-3}\right)\end{array}$ & $d_{\mathbf{w}} / \mathrm{nm}$ & $\begin{array}{c}N \times 10^{-19} / \\
\mathrm{m}^{-3}\end{array}$ & $\begin{array}{c}\text { recipe } \\
\text { no. }\end{array}$ & $\begin{array}{c}\mathrm{TDM}^{a} \\
\text { in recipe? }\end{array}$ & $\begin{array}{c}k_{\mathrm{p}} n / \\
\left(\mathrm{dm}^{3} \cdot \mathrm{mol}^{-1} \cdot \mathbf{s}^{-1}\right)\end{array}$ \\
\hline 10 & 90 & 31.8 & 1 & yes & 41 \\
1 & 90 & 31.8 & 1 & yes & 44 \\
1 & 103 & 21.2 & 1 & yes & 64 \\
0.1 & 103 & 21.2 & 1 & yes & 41 \\
0.01 & 103 & 21.2 & 1 & yes & 14 \\
0 & 102 & 22.3 & 2 & yes & 4 \\
10 & 151 & 6.8 & 1 & yes & 80 \\
1 & 151 & 6.8 & 1 & yes & 87 \\
1 & 156 & 6.2 & 1 & yes & 115 \\
0.1 & 156 & 6.2 & 1 & yes & 99 \\
0.01 & 156 & 6.2 & 1 & yes & 72 \\
10 & 166 & 5.2 & 1 & no & 96 \\
1 & 147 & 7.3 & 2 & no & 48 \\
0.4 & 147 & 7.3 & 2 & no & 45 \\
0.1 & 147 & 7.3 & 2 & no & 5 \\
& & & & &
\end{tabular}

a $\mathrm{TDM}=$ tert -dodecyl mercaptan.

The following brief discussion and Table IV present values and literature references of the parameters used. Very little is reported on the value for the rate coefficient for radical transfer to monomer, $k_{\mathrm{tr}}$, except for an estimation on kinetic grounds by Weerts et al.$^{8,14}$ of $k_{\mathrm{tr}}=$ $0.1 \mathrm{dm}^{3} \cdot \mathrm{mol}^{-1} \cdot \mathrm{s}^{-1}$ and an estimation by the present authors reported elsewhere ${ }^{16}$ of $0.1<k_{\mathrm{tr}}<0.01$. The monomer concentration in the particles, $C_{\mathrm{m}}$, is reported ${ }^{8,14}$ to be 5.6 $\mathrm{mol} \cdot \mathrm{dm}^{-3}$. The diffusion coefficient of monomeric radicals in water, $D^{\prime \prime}$, is calculated according to Wilke and Chang ${ }^{33}$ and found to be $1.5 \times 10^{-7} \mathrm{dm}^{2} \cdot \mathrm{s}^{-1}$. The value of $k_{\mathrm{p} 0}$ may differ from the long-chain value of $k_{\mathrm{p}} ; 3$ however, for simplicity in the following discussion, $k_{\mathrm{p} 0}$ is assumed to be identical to $k_{\mathrm{p}}$. Note that the exit rate coefficient is not a function of the initiator concentration.

Assuming that the Smith-Ewart case I and II approximations hold for the butadiene polymerization system of interest, $\tilde{n}$ can be calculated in terms of the entry and exit rate coefficients: ${ }^{34}$

$$
\bar{n}=\rho /(2 \rho+k)
$$

Calculating the entry and exit rate coefficients via the above-described models offers the possibility of modeling data of $\bar{n}$ versus initiator concentration.

\section{Results and Discussion}

Seeded emulsion polymerizations were performed using a wide range of the initiator concentrations ranging from $10^{-5}$ to $10^{-2} \mathrm{~mol} \cdot \mathrm{dm}^{-3}$ on two different seed latex particle diameters of 90 and $150 \mathrm{~nm}$. The deduction of $k_{\mathrm{p}} \bar{n}$ from the slopes of curves of $-\ln (1-x)$ versus time (the left-hand side of eq 3 ) is elaborately discussed elsewhere. ${ }^{16}$ The results are shown in Table V and Figure 6.

When mercaptan is present, the effect of the initiator concentration on the value of $\bar{n}$ is small, which is in full accord with the literature. ${ }^{1,14}$ The observed small effect cannot be explained by considering the Smith-Ewart case II regime since the $\bar{n}$ values are still significantly below $\tilde{n}$ $=0.5$. Note that the initiator concentration has been varied over 3 orders of magnitude. The insensitivity of $\bar{n}$ becomes even more intriguing considering the model calculations presented in Figure 6 (involving eqs 8, 14, and 15 using the full entry theory). These show $k_{\mathrm{p}} \bar{n}$ versus initiator concentration for two seed latex particle diameters. The values for the rate parameter used are given in Table IV. The data and model calculations presented in Figure 6 lead to the following conclusions:

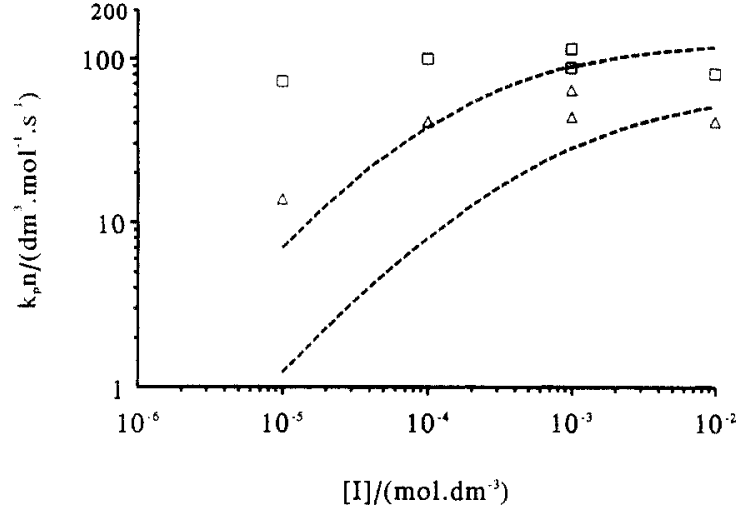

Figure 6. Model calculations (- - ) and experimental data of the product of $k_{\mathrm{p}}$ and $n$ versus [I] for experiments using recipe 1 and seed latex diameters $d_{\mathrm{w}}=90(\Delta)$ and $150 \mathrm{~nm}(\square)$. Note that the almost constant values of $\bar{n}$ are well below the limiting value of $\bar{n}=0.5$.

1. The insensitivity of the rate of polymerization to the initiator concentration is explained by the new limit but only at relatively high initiator concentrations and not at initiator concentrations normally used. The new limit is therefore incapable of solving the problems defined in this paper.

2. The data cannot be fitted with the model utilizing the values for the parameters that accurately fit data of $k_{\mathrm{p}} \tilde{n}$ versus particle diameter. ${ }^{16}$

3. The data confirm the expectations put forward elsewhere ${ }^{16}$ that variation of the initiator concentration could result in finding an almost constant value of $\bar{n}$ but that this could not be used as solid proof for assuming $\bar{n}$ $=0.5$. Determination of the propagation rate coefficient on the basis of such obviously false assumptions, as is done by Morton et al. ${ }^{5}$ in their determination of $k_{\mathrm{p}}$, must be incorrect.

Recently an extension of the entry theory was proposed..$^{35}$ This extension tries to incorporate the effect of minimally water-soluble mercaptans, commonly used as chain-transfer agents. This theory describes an important enhancement of the initiator efficiency of persulfate by chain transfer of the radical activity from water-soluble sulfate radicals to mercaptan dissolved in the water phase. The mercaptyl radicals created in this manner enter particles at a diffusion-limited rate. Although the tertdodecyl mercaptan used in the experiments is mainly in the particle phase, individual molecules will be transferring rapidly between the particle and water phase. The proposed theory assumes a limited but definite aqueous concentration of mercaptan. Kolthoff et $a l^{36}$ report a saturation aqueous water solubility of tert-dodecyl mercaptan of $[\mathrm{TDM}]_{\mathrm{aq}}=3 \times 10^{-5} \mathrm{~mol} \cdot \mathrm{dm}^{-3}$. In order to verify the effect of TDM on the sensitivity of the rate of polymerization to the initiator concentration, experiments were performed using recipe 2 without TDM. As reported earlier ${ }^{19}$ no TDM appears to be necessary to produce reasonable rates of polymerization provided the polymerizations are performed in the absence of emulsifier. ${ }^{13,19}$ The experiments without TDM are performed in a reactor in which TDM was never used to ensure not even the smallest traces of TDM to be present during these polymerizations. The reactor was comparable in every other aspect with the one normally used except that no densitometer was installed. Conversion data are therefore acquired by gravimetry. The seed latexes used for these experiments were polymerized in the same TDM free reactor to ensure completely TDM-free seed latexes. The monomer solubility in the seed latexes was verified by 


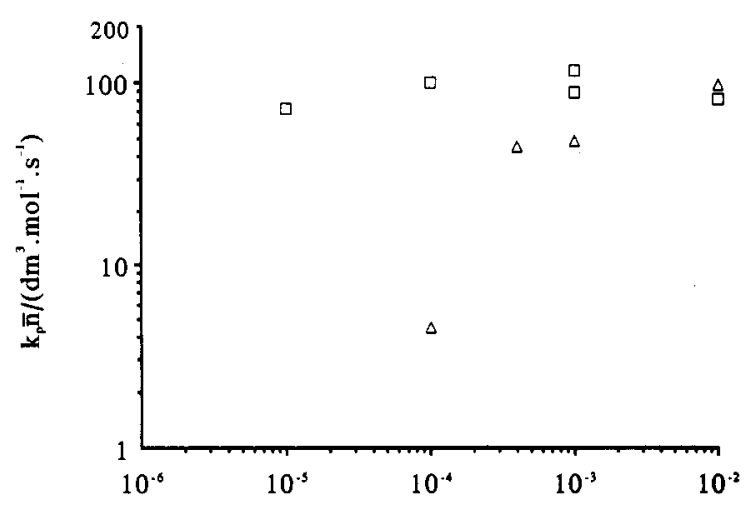

$[\mathrm{I}] /\left(\mathrm{mol} . \mathrm{dm}^{\cdot 3}\right)$

Figure 7. Product of $k_{\mathrm{p}}$ and $n$ versus initiator concentration, [I], using seed latex diameters $d_{\mathrm{m}}=150 \mathrm{~nm}$ for experiments using recipe 1 with TDM $(\square)$ and recipe 2 without TDM ( $\Delta)$.

Table VI. $k_{\mathrm{p}} \mathrm{V}$ Values from Experiments Utilizing Seed Lateres of Weight-Average Diameter $d_{\nabla}=150 \pm 6 \mathrm{~nm}\left(N_{\nabla}\right.$ $\simeq 6.5 \times 10^{10} \mathrm{~m}^{-8}$ ) and Various Initiator Concentrations, [I]

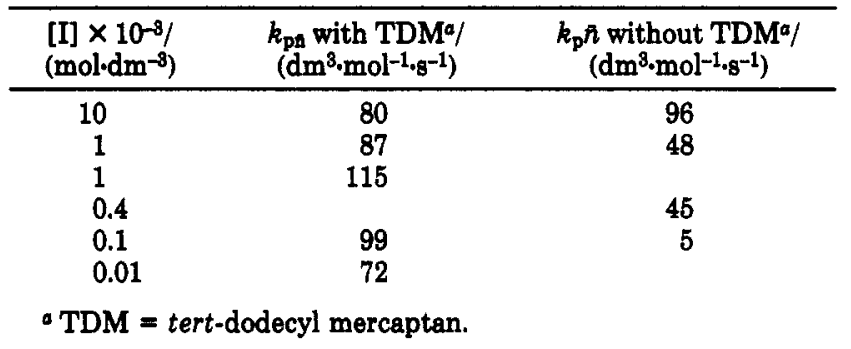

swelling the latexes with the required amount of butadiene in a glass model reactor. After swelling no separate monomer layer could be detected. It was concluded that latexes prepared without TDM exhibit the same monomer swelling as compared with normal latexes. The steadystate slopes of plots of $-\ln (1-x)$ versus time are linear for seeded polymerizations without TDM. Weerts et al. ${ }^{13}$ report that the monomer concentration in the polymer is not affected by the gel content of the polymer over a large range. Bhakuni ${ }^{37}$ also observed that network formation within the latex particles has no influence on the saturation monomer solubility in the polymer. Hence, the linearity of the plots of $-\ln (1-x)$ versus time is expected since the monomer concentration is not affected by the absence of TDM during preparation of the seed and during subsequent seeded polymerization.

In Figure 7 and Table VI values for $k_{\mathrm{p}} \bar{n}$ versus initiator concentration determined in polymerizations with TDM $(\square)$ and without TDM $(\Delta)$ on seed latexes with particle diameter $d_{\mathrm{w}}=150 \mathrm{~nm}$ are shown.

The results shown in Figure 7 are of major importance to this paper. The results show that the presence of TDM has a major effect on the initiator efficiency. Note that the presence of TDM only affects the low initiator concentration region of the range observed. At high initiator concentration, $[\mathrm{I}] \geq 10^{-2} \mathrm{~mol} \cdot \mathrm{dm}^{-3}$, the influence of TDM on $k_{\mathrm{p}} \tilde{n}$ is not significant. The experiments described elsewhere ${ }^{13,19}$ on $a b$ initio emulsifier free emulsion polymerization of butadiene in the presence and absence of TDM are not in contradiction with the currently described experiments because the ab initio experiments were performed at high initiator concentration, [I] $\geq 10^{-2}$ mol. dm ${ }^{-3}$ (i.e., the region in the [I] range that is not influenced by the presence of TDM). Moreover, both authors report an effect of TDM on the particle size distribution (PSD) and particle number obtained. This observation confirms an effect of TDM on the kinetics of nucleation since the PSD and particle number are known

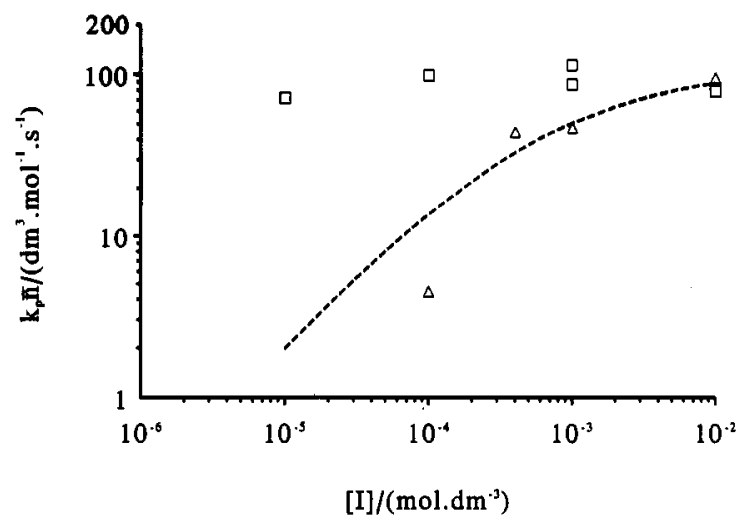

Figure 8. Model calculations (-..) using a value for the rate coefficient of radical transfer to monomer of $k_{\mathrm{tr}}=0.05$ $\mathrm{dm}^{3} \cdot \mathrm{mol}^{-1} \cdot \mathrm{s}^{-1}$, a value for the rate of bimolecular termination in the water phase of $k_{\mathrm{t}}=2 \times 10^{9} \mathrm{dm}^{3} \cdot \mathrm{mol}^{-1} \cdot \mathrm{g}^{-1}$, and experimental data of Figure 7 (with TDM, 口; without TDM, $\Delta$ ).

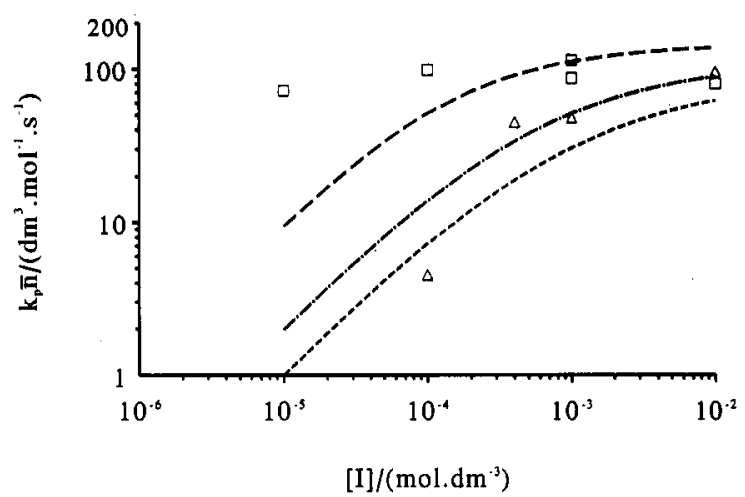

Figure 9. Model calculations using a range of values for the rate coefficient of radical transfer to monomer of $k_{t r}=0.1-0.01$ $\mathrm{dm}^{3} \cdot \mathrm{mol}^{-1} \cdot \mathrm{g}^{-1}$, a value for the rate of bimolecular termination in the water phase of $k_{\mathrm{t}}=2 \times 10^{9} \mathrm{dm}^{3} \cdot \mathrm{mol}^{-1} \cdot \mathrm{s}^{-1}$, and experimental data of Figure 7 [ with TDM, $\square$; without TDM, $\Delta ; k_{t r}=0.1(\cdots)$, $0.05(-\cdot-), 0.01(--)]$.

to be influenced by entry ${ }^{38}$ and exit ${ }^{42}$ of radicals. Figure 8 shows the data of Figure 7 with model calculations using eqs 8,14 , and 15 . Slightly adapted values for the rate parameters $k_{\mathrm{t}}$ and $k_{\mathrm{tr}}$ are used. As is shown elsewhere ${ }^{16}$ the values for these rate parameters are adjustable within certain physically realistic boundaries.

Obviously the data obtained without TDM are fitted adequately with the simple model used. The data of $k_{\mathrm{p}} n$ versus particle diameter reported elsewhere ${ }^{16}$ obtained from experiments in the presence of TDM fit the simple model because these data are obtained at high initiator concentration, $[I] \geq 10^{-2} \mathrm{~mol} \cdot \mathrm{dm}^{-3}$. The fact that the model fits two completely different sets of data $\left(k_{\mathrm{p}} n\right.$ versus particle diameter and versus initiator concentration) is a strong indication of the validity of the model.

In order to verify the effect of the adjustments made for the values of the rate parameters $k_{t}$ and $k_{t r}$, model calculations are performed using $k_{\mathrm{tr}}$ in the range $0.01<$ $k_{\mathrm{tr}}<0.1 \mathrm{dm}^{3} \cdot \mathrm{mol}^{-1} \cdot \mathrm{g}^{-1}$, as proposed elsewhere, ${ }^{16}$ and $k_{\mathrm{t}}$ in the range $10^{9}<k_{t}<10^{10} \mathrm{dm}^{3} \cdot \mathrm{mol}^{-1} \cdot \mathrm{s}^{-1}$, as reported in the literature (see Table IV and Figures 9 and 10).

The data presented in this paper are regrettably subject to limited accuracy. Moreover, the values for $k_{\mathrm{p}} n$ versus initiator concentration determined by model calculations are not significantly affected by variation of the values of the parameters $k_{\mathrm{t}}$ and $k_{\mathrm{tr}}$. As a consequence the data cannot discriminate between the values of $k_{\mathrm{tr}}$ and $k_{\mathrm{t}}$. However, the model calculations of Figures 9 and 10 indicate that the current model is incapable of describing the experiments performed in the presence of TDM. 


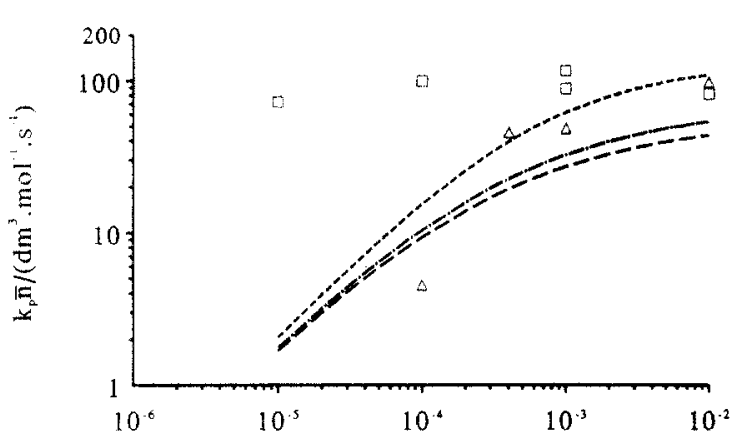

$[\mathrm{I}] /\left(\mathrm{mol}_{\mathrm{dm}} \cdot \mathrm{dm}^{\cdot 3}\right)$

Figure 10. Model calculations using a range of values for the rate coefficient of bimolecular termination in the water phase of $10^{9}<k_{\mathrm{t}}<10^{10} \mathrm{dm}^{3} \cdot \mathrm{mol}^{-1} \cdot \mathrm{s}^{-1}$, a value for the rate coefficient of radical transfer to monomer of $k_{\text {tr }}=0.05 \mathrm{dm}^{3} \cdot \mathrm{mol}^{-1} \cdot \mathrm{s}^{-1}$, and experimental data of Figure 7 [with TDM, $\square$; without TDM, $\Delta$; $\left.k_{\mathrm{t}}=10^{9}(\cdots), 7 \times 10^{9}(---), 10^{10}(--)\right]$.

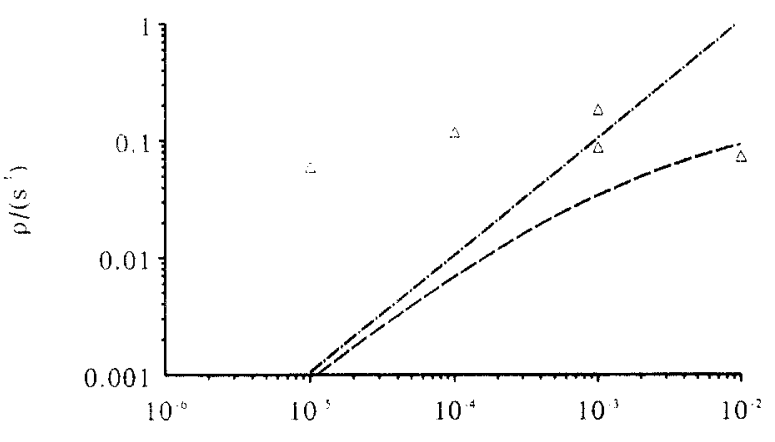

$[\mathrm{I}] /\left(\mathrm{mol} . \mathrm{dm}^{-3}\right)$

Figure 11. Model calculations $\rho$ using (1) the full eq $8(--),(2)$ only the left-hand side of eq 8 (i.e., assuming $100 \%$ efficiency) $(--)$, and (3) experimental $\bar{n}$ data of Figure 7 and values for $k$ using eq $14(\Delta)$.

Much effort was directed into quantitatively describing the experimental data obtained from experiments in the presence of TDM by using the model proposed by Maxwell et $a l .{ }^{35}$ The model describes the effect of mercaptan as an enhancement of the initiator efficiency. From the plots presented in the paper of Maxwell et al. it is clear that an enhancement of the initiator efficiency is significantly only at high initiator concentration, which is not in accord with the present data, as these show a larger effect at lower initiator concentration. However, at the TDM concentrations utilized in this experiment $(\approx 1 \%$ of the saturation aqueous concentration) the model of Maxwell et al. suggests that TDM would have no effect on entry or the $R_{\mathrm{pol}}$.

The initiator efficiency is already very high at low initiator concentration which is clear from Figure 5 , where the curves of $\rho$ versus [I] become similar for different values of $z$ (deduced from the fact that $z$ is only incorporated in the efficiency term of eqs 7 and 8). Initiator efficiency is high at low initiator concentration because radical oligomers can grow to surface-active length without being subject to termination. This is because of the low concentrations of aqueous phase sulfate radicals. This insight is used to further evaluate the effect of TDM on the rate of polymerization. The experimental entry rate coefficient in the presence of TDM is calculated using the experimental $\bar{n}$ values and exit rate coefficients using eq 14. These values are plotted in Figure 11 together with entry rate coefficients calculated with eq 8 and with entry rate coefficients calculated with only the left-hand side of eq 8 (i.e., the $100 \%$ efficiency value of the entry rate coefficient: $\left.2 k_{\mathrm{d}}[\mathrm{I}] N_{\mathrm{a}} / N\right)$.

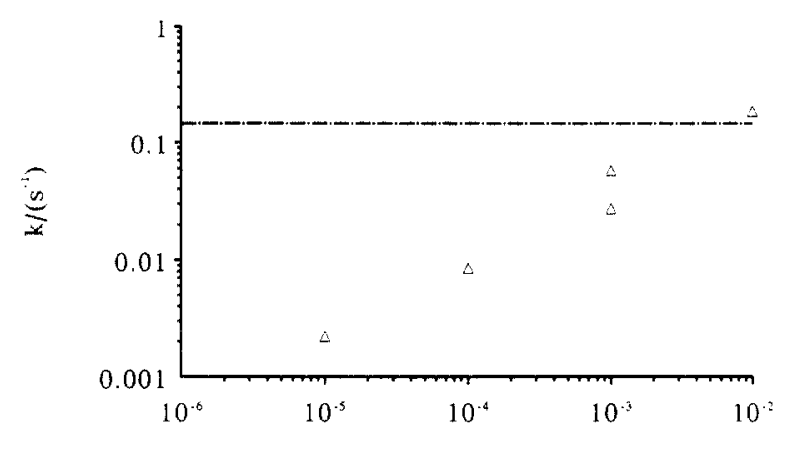

$[\mathrm{I}] /\left(\mathrm{mol}_{\mathrm{dm}} \mathrm{dm}^{-3}\right)$

Figure 12. Model calculations of the radical exit rate coefficient $k$ using (1) the full eq $14(-,-)$ and (2) experimental $n$ data of Figure 7 and values for the entry rate coefficient $\rho$ using eq $8(\Delta)$.

From Figure 11 it can be concluded that in order to reach the experimental $\bar{n}$ values using the exit rate coefficient of eq 14 more radical entry is needed than initiator dissociation allows for. This could only be explained by an enhancement of persulfate dissociation by TDM. The effect of TDM on the dissociation rate coefficient $k_{\mathrm{d}}$ is well described in the literature. Kolthoff et al. ${ }^{39}$ report that mercaptan does not react with persulfate and does not enhance the dissociation rate of persulfate, neither in the emulsion polymerization of styrene nor when directly determined in emulsifier solutions. ${ }^{36}$ Contrary to popular opinion, Kolthoff et al. never reported an enhancement of the dissociation rate of persulfate by mercaptans. An effect of mercaptan on the dissociation rate of persulfate is, however, reported by Blackley ${ }^{7}$ in his well-known book. But it is not clear who reported this and it is definitely not reported by Kolthoff et al. ${ }^{2}$ Measurements reported by Weerts et al. ${ }^{8}$ give the $k_{\mathrm{d}}$ of persulfate during actual emulsion polymerizations as a function of the dresinate 214 concentration. At low dresinate 214 concentrations the value of $k_{\mathrm{d}}$ compares excellently with the value of Kolthoff et al. ${ }^{40}$ measured in pure water $(0.1 \mathrm{M} \mathrm{NaOH})$. The emulsion polymerization performed by Weerts et al. contained TDM $(1 \%$ on monomer) which is not stated directly in the paper but is deduced from the fact that polymerizations without TDM are severely retarded in the presence of dresinate 214 . The literature evaluation given above leaves but one conclusion: TDM has no effect on the dissociation rate of persulfate. In Table $\mathrm{V}$ the results of a thermal experiment (i.e., in the absence of initiator) are shown. Thermal rates are known to be comparable with initiator concentrations of $10^{-4}-10^{-5} \mathrm{~mol} \cdot \mathrm{dm}^{-3} \cdot{ }^{41}$ The results of the thermal polymerization indicate that TDM is not a radicalforming species itself. The thermal experiment shows that the $\bar{n}$ values found in experiments in the presence of TDM are not completely independent of the initiator concentration. At low initiator concentration (i.e., the thermal equivalent) the $\bar{n}$ was decreased. This indicates that TDM shifts the plot of $\bar{n}$ versus initiator concentration to higher values of $\bar{n}$ by an effect operating on the radical loss mechanisms.

The results of Figure 11 seem to point to an effect of TDM on the exit rate coefficient. The exit rate coefficients calculated using experimental values of $\bar{n}$ in the presence of TDM and entry rate coefficients using eq 8 are shown in Figure 12.

From Figure 12 it is clear that the exit rate coefficients must be decreased considerably by TDM to account for the experimental $\bar{n}$ values. Kolthoff et al. ${ }^{2}$ showed, in their experiments conducted in order to illuminate the promoting effect of mercaptan, that the conversion reached 
during $a b$ initio butadiene emulsion polymerization after $12 \mathrm{~h}$ was not affected by variations of $0.005-1 \%$ on monomer of a commercial mixture of $n$-dodecyl mercaptans (given that a minimum amount of mercaptan was present). Whether the particle number varies is not mentioned by the authors, and the initiator concentration used was high, $[\mathrm{I}]=6 \times 10^{-3} \mathrm{~mol} \cdot \mathrm{dm}^{-3}$. One could deduce that the data reported by Kolthoff suggest that the mercaptan concentration does not significantly affect radical desorption. However, since in ab initio experiments the particle number might change considerably as a result of changes in the exit rate coefficient, the data are too ambiguous to be used in the present context. Moreover, the initiator concentration used is high. Nomura et al..$^{42}$ conclude that $n$-dodecyl mercaptan (NDM) does not enhance radical desorption since it has no effect on the rate of polymerization nor particle number in the emulsion polymerization of styrene $\left([\mathrm{I}]=5 \times 10^{-3} \mathrm{~mol} \cdot \mathrm{dm}^{-3}\right)$. From Nomura's work one is tempted to conclude that the NDM concentrations varying from $2.7 \times 10^{-5}$ to $1.1 \times 10^{-4} \mathrm{~mol} \cdot \mathrm{g}^{-1}$ do not decrease radical loss via exit since this would result in a strong rise in $\bar{n}$. However, the system used was styrene at $50^{\circ} \mathrm{C}$ using an initiator concentration of $5 \times 10^{-3}$ mol. $\mathrm{dm}^{-3}$, an SDS concentration of $6.25 \mathrm{~g} \cdot \mathrm{dm}^{-3}$, and particle number concentrations of about $10^{17} \mathrm{dm}^{-3}$. Styrene emulsion polymerizations under these conditions are known to behave as a Smith-Ewart case II system (i.e., $\bar{n}$ $=0.5$ ). Thus a decrease in radical desorption has no effect on $\bar{n}$ since it is already at its limiting value. Weerts et al..$^{13}$ report that no significant difference in the rate of polymerization per particle could be measured between ab initio butadiene emulsion polymerization experiments using NDM or TDM ([I] $\left.=13 \times 10^{-3} \mathrm{~mol} \cdot \mathrm{dm}^{-3}\right)$. Hence, no change of the effects observed in this paper is expected from the difference between NDM and TDM since the water solubility of both mercaptans is expected to be on the same order of magnitude as are the transfer rate coefficients. From the literature one is tempted to conclude that mercaptans do not influence the rate of radical desorption, however, all the data described in the literature are obtained at high initiator concentration where, as the present work indicates, no effect of TDM has been found. Moreover, all literature data are obtained from $a b$ initio experiments, and the rate of polymerization is therefore a function of the particle number. Consequently, no unambiguous data are found in the literature to prove that TDM could not significantly decrease radical desorption.

An effect of TDM on radical desorption could be envisaged as follows. Radical desorption is possible via monomeric radicals; thus, the process of desorption always starts with transfer to monomer. ${ }^{24}$ Monomeric radicals can undergo three processes: (1) propagation, described by $k_{\mathrm{p} 0} C_{\mathrm{m}}=320 \times 5.6=1792 \mathrm{~s}^{-1} ;$ (2) desorption, described by $k_{\text {es; }}$; (3) transfer to TDM, described by $k_{\text {trm }}$ [TDM], where $k_{\text {trm }}$ is the rate coefficient for transfer of monomeric radicals to TDM $\left(\mathrm{dm}^{3} \cdot \mathrm{mol}^{-1} \cdot \mathrm{s}^{-1}\right)$ Literature ${ }^{43}$ reports a value for the long-chain limit of $k_{\mathrm{trm}}=20 k_{\mathrm{p}}=6400 . C_{\mathrm{TDM}}$ is the TDM concentration in the particles $\left(\mathrm{mol} \cdot \mathrm{dm}^{-3}\right)$. From recipe $1, C_{\text {TDM }}$ is calculated using a slightly altered version of eq 4 incorporating TDM, leading to $C_{\mathrm{TDM}}=1.4 \times 10^{-2}$ $\mathrm{mol} \cdot \mathrm{dm}^{-3}$. Thus $k_{\mathrm{trm}} C_{\mathrm{TDM}}=89.6 \mathrm{~s}^{-1}$.

Including the third possibility in the probability of escape leads to:

$$
P=\frac{k_{\mathrm{es}}}{k_{\mathrm{es}}+k_{\mathrm{p} 0} C_{\mathrm{m}}+k_{\mathrm{trm}} C_{\mathrm{TDM}}}
$$

Transfer of monomeric radicals to TDM $\left(89.6 \mathrm{~s}^{-1}\right)$ occurs significantly less frequently than propagation $\left(1792 \mathrm{~s}^{-1}\right)$. Any effect of TDM on radical desorption is therefore hard to imagine unless the rate coefficient of transfer from a monomeric radical to TDM is significantly larger than that of its long-chain limit. However, even if the exit rate coefficient were given by eq 16 , this would not yet explain how the exit rate coefficient changes with initiator concentration. This consideration implies that the following issues are important in the butadiene emulsion polymerization:

1. Exit and reentry of monomeric radicals. This would allow exit to depend on the initiator concentration via termination of exited radicals involving initiator or through the effect of $\bar{n}$ on the fate of reentered radicals. Complicated models ${ }^{4-49}$ including these processes exist but are not readily utilized due to the large number of adjustable parameters. Further work is being done on the subject. ${ }^{50}$

2. There may be another process operating on the radical loss process not considered so far.

The reported promoting effect of mercaptans 2,13 (i.e., the observation that butadiene emulsion polymerization using fatty acid soap based emulsifiers is only polymerized at a reasonable rate when small amounts of mercaptan are present) remains unexplained by the current findings. Both Kolthoff et al. ${ }^{36}$ and Weerts et al. ${ }^{13}$ show that the presence of emulsifier is but one clue in unravelling the promoting effect. It is important to note that the enhancement of the rate of polymerization by TDM in this paper may occur concurrently with the promoting effect. Literature data obtained in the presence of fatty acid soaps suggest chemistry involving the fatty acid soap is important. This matter will be discussed separately. ${ }^{51}$

\section{Conclusions}

A recipe was developed starting a seeded polymerization at $w_{\mathrm{p}}=0.72$, yielding $-\ln (1-x)$ versus time curves with only one linear region from which $\bar{n}$ values could be obtained comparable to values obtained from recipes starting at $w_{\mathrm{p}}=0.6$. Experiments show that data of $k_{\mathrm{p}} n$ obtained in the presence of TDM are virtually independent of the initiator concentration, which is not predicted by model calculations. Experiments in the absence of TDM show that data of $k_{\mathrm{p}} \tilde{n}$ strongly depend on the initiator concentration; this data could be adequately fitted with model calculations. The used model is therefore capable of fitting two separate sets of data of $k_{\mathrm{p}} n$ versus particle diameter and $k_{\mathrm{p}} \bar{n}$ versus initiator concentration. The earlier reports of the independence of $\bar{n}$ of the initiator concentration are explained as an effect of TDM. The data suggest that radical loss via desorption is decreased in the presence of TDM. How exactly TDM affects radical loss cannot yet be explained.

Acknowledgment. The authors are indebted to DSM Research, Geleen, The Netherlands, for financially supporting this work.

\section{References and Notes}

(1) Bovey, F. A.; Kolthoff, I. M.; Medalia, A. I.; Meehan, E. J. In Emulsion Polymerization; Interscience Publishers: New York, 1955.

(2) Kolthoff, I. M.; Harris, W. E. J. Polym. Sci. 1947, $2,41$.

(3) Morton, M.; Salatiello, P. P. J. Polym. Sci. 1951, 6, 225.

(4) Morton, M.; Salatiello, P. P.; Landfield, H. J. Polym. Sci. 1952, 8,111 .

(5) Morton, M.; Salatiello, P. P.; Landfield, H. J. Polym. Sci. 1952, $8,215$.

(6) Morton, M.; Salatiello, P. P.; Landfield, H. Ind. Eng. Chem. $1952,44,739$. 
(7) Blackley, D. C. In Emulsion Polymerization-Theory and Practice; Applied Publishers Ltd.: London, 1975; pp 291-300.

(8) Weerts, P.A. Emulsion Polymerization of Butadiene a Kinetic Study. Ph.D. Thesis, Eindhoven University of Technology, Eindhoven, The Netherlands, 1990.

(9) Weerts, P. A.; van der Loos, J. L. M.; German, A. L. Polym. Commun. 1988, 29, 278.

(10) Weerts, P. A.; van der Loos, J. L. M.; German, A. L. Makromol. Chem. 1989, 190, 777.

(11) Weerts, P. A.; van der Loos, J. L. M.; German, A. L. Makromol. Chem. 1990, 191, 2615.

(12) Weerts, P. A.; van der Loos, J. L. M.; German, A. L. Makromol. Chem. 1991, 192, 1993.

(13) Weerts, P. A.; van der Loos, J. L. M.; German, A. L. Makromol. Chem. 1991, 192, 2009.

(14) Weerts, P. A.; German, A. L.; Gilbert, R. G. Macromolecules $1991,24,1622$

(15) Maxwell, I. A.; Morrison, B. R.; Napper, D. H.; Gilbert, R. G Macromolecules 1991, 24, 1629.

(16) Verdurmen, E. M.; Dohmen, E. H.; Verstegen, J. M.; Maxwell, I. A.; German, A. L. Macromolecules 1993, 26, 268.

(17) Deibert, S.;Bandermann, F.; Schweer, J.; Sarnecki, J. Makromol. Chem., Rapid Commun. 1992, 13, 351 .

(18) Verdurmen, E. M. Particle Nucleation and Growth in Butadiene Emulsion Polymerization. Ph.D. Thesis, Eindhoven University of Technology, Eindhoven, The Netherlands, 1993.

(19) Verdurmen, E. M.; Albers, J. G.; Dohmen, E. H.; Zirkzee, H.; Maxwell, I. A.; German, A. L., submitted to J. Polym. Sci., Part A: Polym. Chem. Ed.

(20) Gilbert, R. G.; Napper, D. H. In Polymerizations in Emulsions: Comprehensive Polymer Science; Eastmond, G. C., Ledwith, A., Russo, S., Sigwalt, P., Vol. Eds.; Allen, G., Bevington, J. C., Eds.; Pergamon: New York, 1989; Vol. 4, Chapter 11, pp 171218.

(21) Maxwell, I. A.; Kurja, J.; Van Doremaele, G. H. J.; German, A. L.; Morrison, B. R. Makromol. Chem. 1992, 193, 2049.

(22) Russel, G. T.; Napper, D. H.; Gilbert, R. G. Macromolecules 1988, 21,2141.

(23) Russel, G. T.; Napper, D. H.; Gilbert, R. G. Macromolecules $1992,29,2459$.

(24) Ugelstad, J.; Hansen, F. K.In Emulsion Polymerization;Piirma, I., Ed.; Academic Press: New York, 1982.

(25) Maxwell, I. A. Kinetic Processes in Emulsion Polymerization Ph.D. Thesis, Sydney University, Sydney, Australia, 1990.
(26) Kolthoff, I. M.; Miller, I. K. J. Am. Chem. Soc. 1951, 73, 3055.

(27) Sangster, D. F.; Davison, A. J. Polym. Sci. 1975, 49, 191.

(28) Dainton, F. S.; James, D. G. L. J. Polym. Sci. 1959, 39, 299.

(29) Dainton, F. S.; Eaton, R. S. J. Polym. Sci. 1959, 39, 313.

(30) Fischer, H. Makromol. Chem. 1966, 98, 179.

(31) Reed, C. D.; McKetta, J. J. J. Chem. Eng. Data 1959, 4, 294.

(32) Ugelstad, J.; Hansen, F. K. Rubber Chem. Technol. 1976, 49, 536.

(33) Wilke, C. R.: Chang, P. Am. Inst. Chem. Eng. J. 1955, 1, 264

(34) Smith, W. V.; Ewart, R. H. J. Chem. Phys. 1948, 16, 592.

(35) Maxwell, I. A.; Morrison, B. R.; Napper, D. H.; Gilbert, R. G. Makromol. Chem. 1992, 193, 303.

(36) Kolthoff, I. M.; Miller, I. K. J. Am. Chem. Soc. 1951, 73, 5118.

(37) Bhakuni, R. S. Kinetics of the persulfate-mercaptan emulsion polymerization of butadiene. Ph.D. Thesis, University of Akron, Akron, OH, 1964; Chem. Abstr. 1974, 62, 353.

(38) Feeney, P. J.; Napper, D. H.; Gilbert, R. G. J. Colloid Interface Sci. 1987, 118, 493 .

(39) Kolthoff, I. M.; O'Connor, P. R.; Hansen, J. L. J. Polym. Sci. $1955, X V, 459$

(40) Kolthoff, I. M.; Miller, I. K. J. Am. Chem. Soc. 1951, 73, 3055.

(41) Maxwell, I. A.; Napper, D. H.; Gilbert, R. G. J. Chem. Soc., Faraday Trans. 1987, 83, 1449.

(42) Nomura, M.; Minamino, Y.; Fujita, K.; Harada, M. J. Polym. Sci., Polym. Chem. Ed. 1982, 20, 1261

(43) Brandrup, J.; Immergut, E. H. Polymer Handbook, 2nd ed.; Wiley: New York, 1975.

(44) Maxwell, I. A. Kinetic Processes in Emulsion Polymerization. Ph.D. Thesis, Sydney University, Sydney, Australia, 1990.

(45) Gilbert, R.G.; Napper, D. H.; J.Macromol. Sci., Rev. Macromol. Chem. Phys. 1983, C23, 127.

(46) Mead, R. V.; Poehlein, G. W. J. Appl. Polym. Sci. 1989, 38, 105.

(47) Nomura, M. Desorption and Reabsorption of Free Radicals in Emulsion Polymerization. In Emulsion Polymerization; Piirma, I., Ed.; Academic Press: New York, 1982; p 191.

(48) Asua, J. M.; Sudol, E. D.; El-Aasser, M. S. J. Polym. Sci., Part A: Polym. Chem. 1989, 27, 3903.

(49) Hansen, F. K.; Ugelstad, J. Makromol. Chem. 1979, 180, 2423.

(50) Verdurmen, E. M.; Geurts, J. M.; Maxwell, I. A.; German, A. L., accepted for publication in Makromol. Chem.

(51) Verdurmen, E. M.; Verstegen, J. M.; German, A. L., accepted for publication in Makromol. Chem. 